\title{
Management strategies for red shrimp (Aristeus antennatus) fisheries in the Catalan sea (NW Mediterranean) based on bioeconomic simulation analysis
}

\author{
Francesc Maynou a , Francesc Sardà, Sergi Tudela and Montserrat Demestre \\ Institut de Ciències del Mar (CSIC), Psg. Marítim de la Barceloneta 37-49, 08003 Barcelona, Spain
}

Received 29 September 2005; Accepted 24 April 2006

\begin{abstract}
We present a simulation bioeconomic model based on an age-structured population biological sub-model and an economic sub-model with vessel-specific dynamics, applied to two red shrimp (Aristeus antennatus) stocks in the NW Mediterranean. The model is dynamic, the economic sub-model is disaggregated at the level of vessel and the two sub-models are linked by means of a fishing mortality vector. We analyzed the projection of selected indicators (catches, overall profits, fishing mortality and spawning stock biomass) for the target species of the deep-water trawl fishery in the NW Mediterranean, red shrimp. We built three alternative management scenarios based on input control and we examined the performance of these management strategies against the current management policies. The three alternative management strategies were: $i$ ) increase the cost of effort by eliminating the fuel tax exemption currently in place, ii) limit the nominal effort level (days at sea) to current levels, in order to offset the increasing trend observed in the last decade, and iii) change the selectivity patterns of the trawl by increasing mesh size. Our results show that for the two stocks analyzed, any of the three management measures (input controls) would be beneficial both to the stock and the fleets (over the medium and long terms) when compared with the projections over time of the status quo. Improving the selectivity of the fishing gear is more beneficial than limiting nominal effort or increasing the cost of effort. Comparing the performance of the management strategies on two stocks, one heavily fished and the other moderately so, we show that none of these management measures is able to substantially redress the situation of a heavily fished stock, implying that for the full recovery of heavily fished red shrimp stocks, we need to contemplate even stricter measures of management.
\end{abstract}

Key words: Bioeconomic analysis / Fishery management / Input control / Simulation / Deep-water fisheries / Red shrimp / Aristeus antennatus / NW Mediterranean

Résumé - Stratégies de gestion pour la pêche de crevettes rouges (Aristeus antennatus) en mer catalane (nord-ouest Méditerranée) basées sur une analyse de simulation bioéconomique. Nous présentons un modèle de simulation bioéconomique, basé sur un sous-modèle d'une population structurée en âge et d'un sous-modèle économique d'une flottille spécifique, appliqué à deux stocks de crevettes rouges ou «gambas » (Aristeus antennatus) du nord-ouest de la Méditerranée. Le modèle est dynamique, le sous-modèle économique est individualisé au niveau du chalutier, et les deux sous-modèles sont liés par l'intermédiaire de la mortalité par pêche. Nous analysons la projection des indicateurs sélectionnés (captures, profits, mortalité par pêche et biomasse du stock de géniteurs) pour ces crevettes, espèces-cibles de la pêche chalutière profonde du nord-ouest de la Méditerranée. Nous avons construit 3 scénarios possibles de gestion, basés sur le contrôle des gains et nous examinons leur performance par rapport aux politiques courantes de gestion. Les trois stratégies alternatives de gestion sont : 1) augmenter le coût de l'effort de pêche, en supprimant l'exemption de la taxe de gasoil, actuellement en vigueur; 2) limiter le niveau d'effort nominal (nombre de jours de mer) dans le but de compenser la tendance à l'augmentation, observée depuis dix ans, et 3) changer la configuration de sélectivité du chalut, en augmentant la taille des mailles. Nos résultats montrent que pour les deux stocks analysés, aucune de ces trois mesures de gestion (contrôle des gains) ne serait bénéfique, à la fois pour le stock et pour la flottille (sur le long- et le moyen terme) lorsqu'elles sont comparées aux projections dans le temps du statu quo. Améliorer la sélectivité de l'engin de pêche est plus avantageux que le fait de limiter l'effort nominal ou d'augmenter le coût de l'effort de pêche. En comparant les performances des stratégies de gestion sur deux stocks, l'un lourdement exploité, et l'autre plus modérement, nous montrons qu'aucune des ces mesures n'est capable de redresser la situation, de façon substantielle, d'un stock intensément exploité, ce qui implique que des mesures plus strictes doivent être envisagées pour la reconstitution complète de ces stocks de crevettes rouges.

\footnotetext{
a Corresponding author: maynouf@icm.csic.es
} 


\section{Introduction}

The red shrimp (Aristeus antennatus) constitutes important deep-water trawl fisheries in the Western Mediterranean (Bas et al. 1985). The fishery is very lucrative, due to the high commercial value of the product, but involves high costs and risks as it is conducted in deep-waters of the continental slope (450-900 m, although the species is distributed down to $3000 \mathrm{~m}$ depth) and near submarine canyons (Fig. 1; Sardà et al. 1994; Sardà et al. 1997; Tudela et al. 2003). The red shrimp is the most valuable invertebrate species caught in the Western Mediterranean, both in term of quantity caught and economic value and is targeted by the larger vessels of the trawl fleet segment. Studies on the biology and population dynamics of this species are abundant (Demestre and Martín 1993; Demestre and Lleonart 1993; Sardà et al. 1994), but economic data on this fishery are scarce.

Figure 2 shows the trend in the red shrimp catches for the two ports analyzed here, Barcelona and Blanes, from 1992 to 2004. In both ports a decreasing trend in the production is evident, both for the official catch data (as recorded by the catch statistics authority) and for the reconstructed catch series from the sampling programs carried out by our Institute. Despite this apparent decrease in production, the fishery continues to be very lucrative because prices have increased in real terms by $250 \%$ over the same time span, from $c a .20 € \mathrm{~kg}^{-1}$ in 1992 to $50 € \mathrm{~kg}^{-1}$ in 2004 (occasionally, up to $100 € \mathrm{~kg}^{-1}$ ), due to the consumer demand of this high-quality product. The trend of prices over a 20-year period (1962-1983: Tobar and Sardà 1987) showed an important unit price increase: while the price of most other demersal species in the period considered increased 5 times, the price of Aristeus antennatus increased 13 times. If we consider current prices for this species (average $50 € \mathrm{~kg}^{-1}$ in 2004 at first sale) it is clear that the market value of this species has produced strong incentives for the exploitation of this resource. Analyses based on Virtual Population Analysis (VPA) techniques point to fullor over-exploitation of this resource for many stocks analysed (Demestre and Lleonart 1993; Carbonell et al. 1999; GarcíaRodríguez and Esteban 1999). Even with overall decreasing catches, the fisheries can be sustained in the short term from the economic point of view due to the strong valorization of the resource.

A key to the high profitability of this fishery is that the costs are partly subsidized. There is notably an exemption on fuel tax, which amounted to $50 \%$ of the fuel cost in 1999 , while subsidies for fleet modernization imply, in practice, a strong incentive to increase engine power and fishing effort. Total nominal effort on the Spanish ports cannot increase by law, i.e. no new trawlers can enter the fishery in the area of influence of a port (Fig. 1), but given the decreasing productivity of continental shelf and upper slope fishing grounds, more and more vessels especially the larger trawlers) of a given port deploy their fishing effort in the deeper fishing grounds, which in our study area are 2-3 hour steaming from the base port. In this sense, effort (in terms of activity: fishing days year ${ }^{-1}$ ) is continuously increasing on the deep-water shrimp stocks.

Considering the high social and economic importance of this resource in the Mediterranean and the observation that production is mostly determined by economic incentives, it

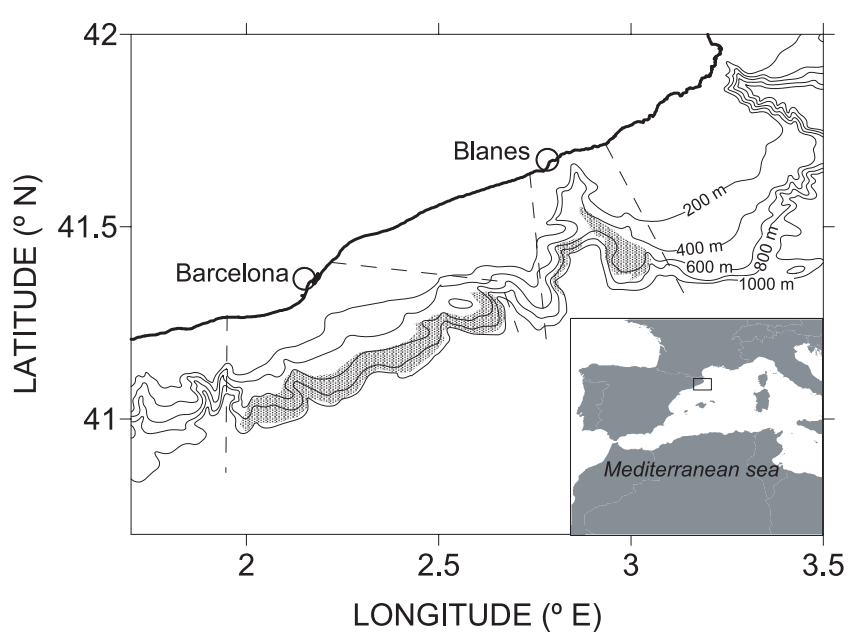

Fig. 1. Map of the study area, showing the location of the ports analysed, the area of influence of their fleets (dotted lines) and the fishing grounds of the red shrimp trawl fishery (shaded).

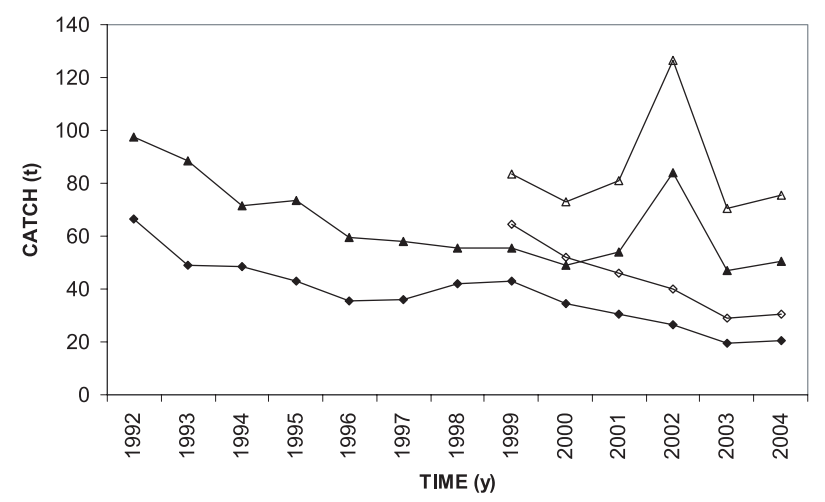

Fig. 2. Official landings (filled symbols) and estimated catches (empty symbols) for the Barcelona (diamonds) and Blanes (triangles) red shrimp fisheries, in ton for the period 1992-2004.

is necessary to conduct bioeconomic analyses of this fishery to study the current exploitation pattern and assess the effect of management measures that could be implemented in the near future, complementing the studies based on biological data conducted until now. Mediterranean fisheries are not managed adaptively as other fisheries in Atlantic Europe or North America (Lleonart et al. 2003). This means that the assessments of the stock in one year are not used to implement new management measures for the following year. The status quo of the management regime of Mediterranean trawl fisheries derives from European Regulation 1626/1994, which imposes input controls to the trawl fishery in the form of a minimum mesh size of $40 \mathrm{~mm}$ and a limitation on the horsepower of new vessels (500 HP). Additionally, at the level of Autonomous Community of Catalonia, other input controls are in place, such as limiting the number of days at sea and daily fishing hours and prohibiting new entrants to the trawl fishery in the area of influence of a given harbour. These input controls are in fact a means to limit nominal effort on the entire trawl fishery. However, due to the fact that trawl vessels based in a specific harbour (Barcelona or Blanes) may switch their effort from continental shelf to slope species, the real effort applied to the 
Aristeus antennatus fishery may increase with time. In 2004 a new Common Fisheries Policy was adopted for European fisheries. In the context of Mediterranean fisheries, an Action Plan was drafted, which included a concerted approach to declaring fisheries protection zones, the use of fishing effort as the main instrument in fisheries management, improving fishing techniques so as to reduce the adverse impact on stocks and the marine ecosystem and promoting international co-operation. From these general measures, we built 3 alternative management measures: eliminating the subsidy to fuel costs, limiting effort to historical levels and changing mesh size in order to improve selectivity. It is important to note that deep-water trawl fisheries are not managed separately from other trawl fisheries in the study area; hence imposing new mesh sizes or reducing the number of fishing days for the trawling fleet, justified on the basis of overexploitation of continental shelf resources, will affect deep-water shrimp fisheries.

The successful management of fisheries must take into account biological and economic considerations, including the evaluation of alternative management strategies, as proposed by Horwood (1994). Bioeconomic simulation models (Sparre and Willmann 1993; Seijo et al. 1998; Holland 2000; Ulrich et al. 2002a; 2002b; Holland et al. 2005) are useful tools for forecasting the likely development of fisheries and its impact on ecosystem and society in a broad sense. Bioeconomic models may include management measures or controls appropriate for the case study being analysed: for instance, Holland et al. (2005) used a model based on output controls to analyse a rock lobster fishery in southern New Zealand, while Holland (2000) and Holland and Schnier (2006) explored the use of Marine Protected Areas as a fisheries management measure, and Ulrich et al. (2002b) compared the performance of input controls (effort quotas) and output controls (catch quotas) in a North sea flatfish fishery. In the Mediterranean, fisheries management is based solely on input controls (effort and selectivity measures) that are not adaptively reviewed annually (Lleonart et al. 2003).

We agree with Christensen (1997) that the success of management programs are subject to a clear comprehension of the biology and population dynamics of exploited fish stocks and also upon knowledge of the behavior of fishing fleets. Due to the importance of individual vessel dynamics in the allocation of effort in Mediterranean fisheries (Lleonart et al. 1996; Lleonart et al. 1999), we explore a model that explicitly considers the dynamics of effort and fishing power for individual vessels, based on an empirically derived set of behavioral rules, conceptually similar to individual based models (IBMs) built for fish populations (Werner et al. 2001). Other bioeconomic models based on multi-species dynamics and multi-fleet interactions do exist, such as BEAM IV, developed by Sparre and Willmann (1993) or BECHAMEL (Ulrich et al. 2002a), but treat each fleet as a collection of vessels of the same characteristics, and effectively work at the scale of fleet aggregates.

The objectives of this work are to analyze the effects of different management regimes on deep-water shrimp fisheries, based on a bioeconomic simulation model disaggregated at the vessel level, and to examine the trends in biological and economic indicators, for two representative ports (Barcelona
Table 1. Biological parameters for Aristeus antennatus for the stock exploited by the Barcelona and Blanes fleets. Parameters of the von Bertalanffy growth function: $L_{\infty}, k$ and $t_{0}$. Parameters of the lengthweight relationship: $a, b$. Natural mortality $(M)$ from Demestre and Lleonart (1993).

\begin{tabular}{lr}
\hline$L_{\infty}(\mathrm{mm} \mathrm{CL})$ & 65 \\
\hline$k\left(\right.$ year $\left.^{-1}\right)$ & 0.275 \\
$t_{0}$ (year) & -0.285 \\
$a$ & 0.003332 \\
$b$ & 2.392 \\
Natural Mortality (M) & 0.65 \\
\hline
\end{tabular}

and Blanes, Catalan sea, NW Mediterranean) with different exploitation patterns.

\section{Material and methods}

\section{Data sources}

During 1998-1999, we conducted a EU-funded project ("COCTEL": Analysis of the Mediterranean (including North Africa) deep-sea shrimps fishery: catches, effort and economics, Sardà 2000) to obtain basic biological and economic data of red shrimp fisheries in the countries around the Western Mediterranean (Spain, Italy, Tunisia, Algeria, Morocco). Biological and economic data were obtained from samplings on-board by observers monitoring the fishery weekly from November 1998 to October 1999. Additional economic data was obtained at the local fish market, where the production is auctioned daily. Here we present the results for the ports of Barcelona and Blanes, in NE Spain, and conduct the bioeconomic analysis on these two ports, whose stocks show contrasting exploitation patterns.

The biological data (especially, size frequencies of individuals) were used to reconstruct the virtual population available to each fleet by means of Virtual Population Analysis, VPA, using the program VIT (Lleonart and Salat 1997).

Table 1 shows the growth parameters of the von Bertalanffy growth function established for the red shrimp stock, as well as the parameters of the length-weight relationship. Natural mortality was taken from Demestre and Lleonart (1993). Table 2 shows the reconstructed population $\left(N_{a}\right)$, maturity proportion $\left(M A T_{a}\right)$ and fishing mortality $\left(F_{a}\right)$ by age group resulting from the VPA. Biological parameters were used as input parameters for the biological, age-structured submodel (Tables 1 and 2).

The summary statistics of the economic parameters (costs and revenues) of the trawler fleet conducting the deep-water red shrimp fishery in Barcelona and Blanes are shown in Table 3. Twelve vessels in Blanes and 18 vessels in Barcelona carried out the deep-water shrimp fishery in 1998-1999, working and average of 145 days year ${ }^{-1}$ on this fishery (in the area, the maximum legal working days, or maximum days at sea is 247) and the remaining days on continental shelf fisheries targeting finfish. The maximum permitted daily working time is 12 hours: this includes between 4 and $6 \mathrm{~h}$ of steaming to and from the fishing grounds and 6 to $8 \mathrm{~h}$ of effective fishing time, comprising 1 or 2 trawl hauls. As other trawl fleets 
Table 2. Population parameters for Aristeus antennatus based on VPA: number of individuals at age in the reconstructed population $\left(N_{a}\right)$, proportion of mature individuals at age $\left(M A T_{a}\right)$, fishing mortality at age $\left(F_{a}\right)$.

\begin{tabular}{lrclrcc}
\hline \multicolumn{4}{c}{ Barcelona } & \multicolumn{3}{c}{ Blanes } \\
\hline $\begin{array}{l}\text { Age } \\
\text { (a) }\end{array}$ & $N_{a}$ & $M A T_{a}$ & $F_{a}$ & $N_{a}$ & $M A T_{a}$ & $F_{a}$ \\
\hline 0 & 21804568 & 0 & 0.002 & 22345970 & 0 & 0.040 \\
1 & 8990724 & 0.609 & 0.521 & 11798176 & 0.57 & 0.552 \\
2 & 2684260 & 1 & 1.058 & 3516959 & 1 & 0.978 \\
3 & 557827 & 1 & 1.262 & 681526 & 1 & 0.596 \\
4 & 110394 & 1 & 0.821 & 244597 & 1 & 0.922 \\
5 & 29471 & 1 & 0.687 & 92610 & 1 & 0.400 \\
6 & - & - & - & 37649 & 1 & 0.525 \\
7 & - & - & - & 13515 & 1 & 1.313 \\
\hline
\end{tabular}

in the Mediterranean, our study fleets return daily to the base port to sell the catch fresh at the evening auction. The vessels are relatively large, with an average capital of $488575 €$, a gross tonnage of $81 \mathrm{t}$ and with powerful engines (usually around $1000 \mathrm{HP}$ ) that consume $1244 \mathrm{Ld}^{-1}$ on average.

\section{Bioeconomic model}

The bioeconomic simulation model used is an adaptation of the MEFISTO model (documented in Lleonart et al. 2003), a multi-species, multi-fleet model with technical interactions with one or more fleets competing for one resource (in the sense of Mesnil and Shepherd 1990). The model comprises two interacting sub-models: one defining the population dynamics of the stock and the other defining the vessel dynamics. For the stock sub-model, we followed the general formulation of a fully age-structured model (Ulrich et al. 2002a), but our model differs from BECHAMEL and BEAM IV in that it follows a fully age-structured model for the biology of main species (for which assessment data is available) and treats the production of secondary (by-catch) species as an empirically estimated function of main species, because no biological parameters are available for these species although they contribute significantly to the total revenues of the vessels. Our economic sub-model is original and aims to reflect the specific behavior of Mediterranean fishers (Lleonart et al. 1996; Lleonart et al. 2003): it includes a set of rules that describe the dynamics of individual vessel's effort (in terms of activity: days or hours at sea) and fishing power. The set of vessels that form the fleets in the operating model are those using trawls to target red shrimp in deep-waters of the middle continental slope in the two ports, effectively constituting a métier, in the sense of Ulrich et al. (2002a).

The simulations were run at the basic time unit of 1 year for a projection horizon of 15 years, taking as reference year 1999. Due to the high market value of this species, no discards of red shrimp were reported (cf. Carbonell et al. 2001) and hence fishing mortality due to discards was not included in the model. Conversely, the nominal catches of this species do not always reflect the true landings because a part of the catches are sold outside the official sale market. From our observations, we estimated that $65 \%$ of the catches were sold in

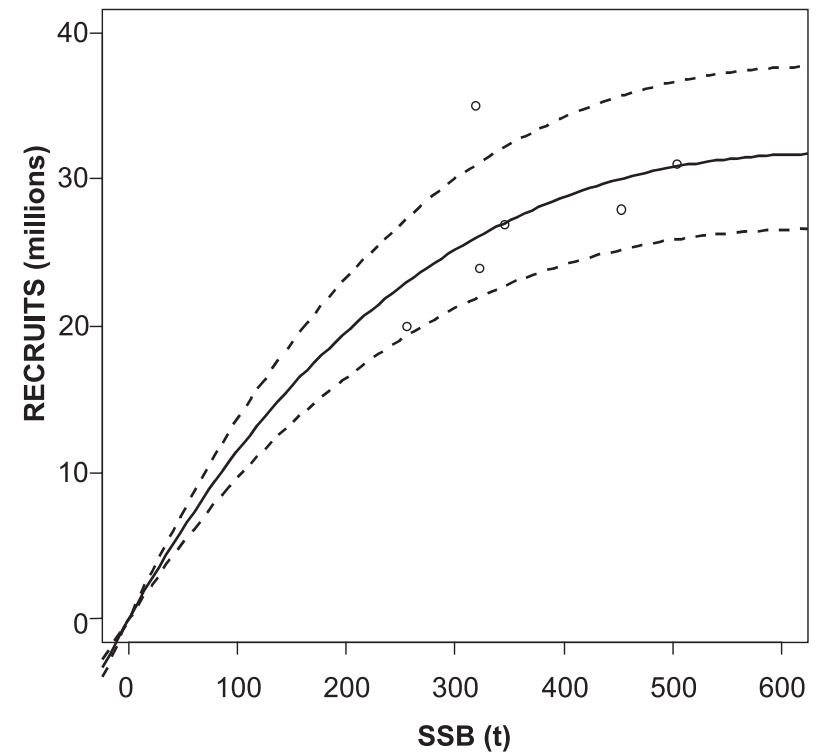

Fig. 3. Spawning Stock Biomass (t) and Recruitment $\left(10^{6}\right.$ individuals) relationship based on data from Demestre and Lleonart (1993). The data were fitted to a Ricker model (bold line) with $\alpha=0.1341$, $\beta=0.00155$ and multiplicative error term $\varepsilon=0.217$. Confidence intervals $(95 \%)$ are shown by dotted lines.

the official market and estimated the real catches, accordingly (Fig. 2). Effort is measured as time at sea: number of days fishing $\times$ working hours day ${ }^{-1}$.

The biological sub-model was run for the red shrimp stock, complemented with a set of bycatch species, such as European hake (Merluccius merluccius), greater fork-beard (Phycis blennoides), conger eel (Conger conger), or monk fish (Lophius sp.). The equations of a fully age-structured model are well known and are not reproduced here. The spawning stock/recruitment relationship was calculated from data in Demestre and Lleonart (1993) based on a 6-year series, which nonetheless produced a reasonable fit to a Ricker recruitment model ( $r=0.58, p=0.014$; Fig. 3 ). The spread of the residuals of this fit were used to calculate an error term to model recruitment uncertainty, giving way to stochastic simulations, following the approach of Holland (2000).

Almost no previous data on costs and revenues were available for these fleets, and the data presented here were obtained by means of specifically designed questionnaires during the COCTEL project (Sardà 2000). The cost structure for the fleets is well-known, as it follows the general pattern for trawlers along the Catalan coast (Lleonart et al. 1999), and was modeled in detail by categorizing the types of costs, as shown below.

The behavior of each individual vessel was modeled following a general set of behavioral rules, which determine how the fishing effort is allocated and how catchability varies with time according to owner's investment in the vessel in order to increase fishing power. Data on daily catch by vessel and species have been provided by the Barcelona and Blanes Fishers' Associations from 1992 to 2004, allowing us to estimate the trends in effort increase for the red shrimp fishery from 1992 to 1999 (taking 1999 as reference year for our 
Table 3. Descriptive statistics with the total (fleet) and average (by vessel) annual values of the economic parameters of the trawlers conducting the deep-water red shrimp fishery in Barcelona (18 vessels) and Blanes (12 vessels), costs, total revenues and capital (see main text for definition of costs).

\begin{tabular}{|c|c|c|c|c|}
\hline & Barcelona fleet & Blanes fleet & $\begin{array}{c}\text { Average for } \\
\text { a vessel Barcelona }\end{array}$ & $\begin{array}{l}\text { Average for } \\
\text { a vessel Blanes }\end{array}$ \\
\hline Trade costs (€, $19 \%$ of production) & 255360 & 4118250 & 14187 & 343188 \\
\hline Variable costs or effort costs $(€)$ & 3831625 & 2282880 & 212868 & 190240 \\
\hline $\begin{array}{l}\text { Value of production in } 1999 \\
\text { (€, main species + commercial bycatch) }\end{array}$ & 13440000 & 21675000 & 746667 & 1806250 \\
\hline Labor costs $(€)$ & 4798108 & 9687985 & 266562 & 807332 \\
\hline Fixed costs $(€)$ & 1071398 & 738684 & 59522 & 61557 \\
\hline Profits ( $€$, net to the owner) & 3483509 & 4847201 & 193528 & 403933 \\
\hline Capital $(€)$ & 8239944 & 5702064 & 457775 & 475172 \\
\hline
\end{tabular}

analyses). For each vessel, increasing fishing effort $\left(E_{t, v}\right)$ coupled with possibly increasing catchability $\left(q_{t, v, a}\right)$ will result in increasing the combined fishing mortality to the stock $\left(F_{t, f l, a}\right)$, but will increase also the costs of fishing. The decrease in marginal cost due to increase in catchability was not taken into account in the model for lack of empirical data to assess this decrease.

The total catch of age $a$ shrimp by fleet $f\left(\mathrm{C}_{t, f l, a}\right)$ is (as a function of biomass $\bar{B}_{t, a}$ ) at each time $t$ of the simulation horizon:

$$
C_{t, f l, a}=F_{t, f l, a} \bar{B}_{t, a}
$$

where $F_{t, f l, a}=q_{t, f l, a} \cdot E_{t, f l}$. The fleet's catch is allocated by vessel assuming that each vessel applies a proportional fishing mortality to the stock and that this proportionality is given by its catchability coefficient $q_{t, v,}$. (vessel's relative fishing power re-scaled by $Q_{f l, \text {, }}$, the catchability coefficient of the fleet for the reference year, that is: $\left.q_{0, f l, .}=Q_{f l, .}\right)$ and the effort $E_{t, v}$ applied (number of fishing days times daily fishing hours). Then, the catch by age for the individual vessel will be:

$$
\begin{aligned}
C_{t, v, a} & =\frac{F_{t, v, a}}{F_{t, f l, a}} C_{t, f l, a} \\
& =\frac{p E f f_{t, v} N F D_{f l} N H D_{f l} Q_{f l, a} q_{t, v} S_{t, f l, a}}{F_{t, f l, a}} C_{t, f l, a}
\end{aligned}
$$

where $S_{t, f l, a}$ is the selectivity-based changes introduced in the catchability term of each vessel and age group, $p E f f f_{t, v}$ is the proportion of effort of vessel $v, N F D_{f}$ is the number of fishing days of the fleet and $N H D_{f l}$ is the number of hours authorized per day for the fleet.

For each vessel, the catches of shrimp by age group are transformed to revenues by the following market equation:

$$
Y_{t, v, a}=C_{t, v, a} p
$$

where $p$ is the unit price. In this application we treat prices as exogenous, as the local production of red shrimp does not dictate the prices fetched by red shrimp.

To the revenues provided by the target stock (red shrimp) we added the revenues obtained by the commercial by-catch (greater fork-beard: Phycis blennoides, conger eel: Conger conger, European hake: Merluccius merluccius and monk fish: Lophius sp., Fig. 4). The proportion and value of the by-catch species were determined from landings data for the monitoring

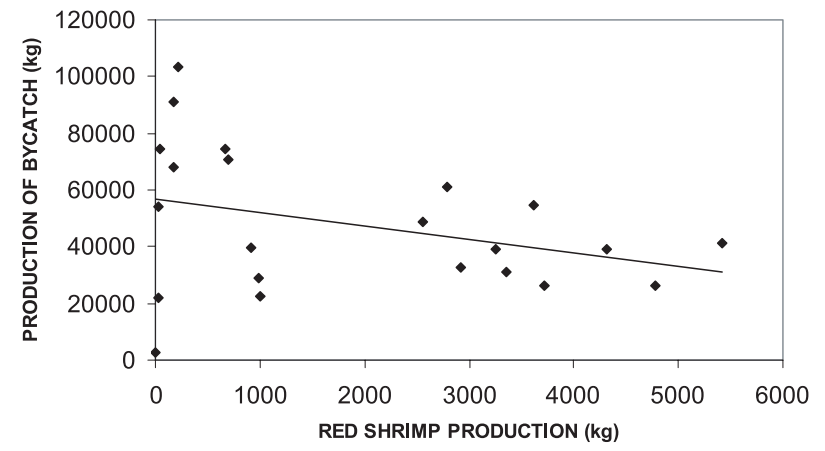

Fig. 4. Production of red shrimp $(\mathrm{kg})$ against production of other species for sampling boats in 1998-1999. Parameters of the linear model fitted are: intercept 56.7 ; slope -0.47 .

period 1998-1999. The value of the commercial by-catch $\left(Y^{b}\right)$ is given empirically as:

$$
Y_{t, v}^{b}=p^{b}\left(\mu^{b}+v^{b} C_{t, v}\right)
$$

where $p^{b}$ is the price of a by-catch species and $\mu^{b}$ and $v^{b}$ are coefficients of the linear regression between catch of the bycatch species and catch of the target species (Fig. 4).

The total revenues by vessel at each time $t$ are:

$$
Y_{t, v}^{T}=Y_{t, v, \cdot}+Y_{t, v}^{b}
$$

From the total revenues, the costs related to fishing effort are substracted, in order to provide a net income. Following the cost structure observed in the Catalonian trawl fisheries, some cost coefficients are computed at the fleet level (e.g. the trade cost fee is the same percentage for all the vessels), while other costs are computed at the vessel level, as relevant. Based on the net income, the behavioral rules stated below describe the decision that each vessel will take regarding the relative effort $\left(p E f f_{t, v}\right)$ that will be applied to the fishery during the next time unit. The seven types of costs deducted are modeled as follows (modified from Lleonart et al. (1996, 1999), we drop the subscript $t$ of the variables for brevity):

i) Trade costs $\left(\mathrm{Col}_{v}\right)$, which include all costs that represent a percentage of the first sale of the catch ex-vessel, such as value added tax, fishermen's association taxes and local taxes:

$$
\operatorname{Co} 1_{v}=c 1_{f l} Y_{t, v}^{T}
$$


where $c 1_{f l}$ is constant for all the vessels in each trawl fleet amounting to $19 \%$ of the sale.

ii) Variable costs (or costs of effort, Co2v): are the costs of fishing effort (fuel consumption, net mending, daily food expenses, ice and lubricant), excluding labor costs. They are a function of the daily cost of fishing by effort and include a part of maintenance costs, such as net mending, which are proportional to effort. For each vessel $v$ we have:

$$
\operatorname{Co} 2_{v}=c 2_{v} \cdot E_{t, v}
$$

where $c 2_{v}$ is the unit cost of effort, computed as: daily fuel cost + daily ice cost + other daily costs (Table 3 ). In our model, it was important to differentiate the contribution of daily fuel cost to the total daily expenses because net fuel price can be used as a control variable.

iii) Labor costs $\left(\mathrm{Co}_{v}\right)$ : In most Mediterranean fisheries the wage of crew members is paid through a share system. Crew members obtain a share of the balance from deducting the common costs from the value of the total sales, following a "broken lay" system. The common costs $\operatorname{Col}_{v}$ and $\operatorname{Co}_{v}$ are deducted from the total revenues resulting in net sales $(M M)$ :

$$
M M_{v}=Y_{v}^{T}-\left(C o 1_{v}+C o 2_{v}\right)
$$

$M M_{v}$ is divided in two parts, one for the owner and another for the crew (including the owner, when the owner is a worker). The part of the owner is used to meet the remaining expenses of the economic activity, while the part of the crew is used to pay the crew's wages (labor costs):

$C o 3_{v}=c 3_{f l} M M_{v}$, where $c 3_{f l}$ is $50 \%$ in the fleets analyzed, although this coefficient may vary in other Mediterranean fisheries. The owner share is $\left(1-c 3_{f l}\right) M M_{v}$.

iv) Fixed costs $\left(\mathrm{Co}_{v}\right)$ : include the yearly costs incurred by each vessel that are fixed and not related to effort, such as harbor fees, fishing license and vessel insurance. They are considered exogenous to the model.

v) Maintenance costs $\left(\operatorname{Co5_{v}}\right)$ : are the costs required to maintain the vessel at its maximum performance level. They are included in the reinstatement of the used capital and repairs. $C 05_{v}$ are divided in two parts. The first part includes the operating costs that are indispensable to meet in order to remain in activity (major reparations, such as engine overhaul). The second part includes the other maintenance costs that are avoidable and result in capital depreciation when they are not met, such as minor reparations or painting, that are avoided when net returns are negative. The total yearly maintenance costs were divided, based on empirical observations, in $70 \%$ indispensable costs and 30\% avoidable costs for each vessel.

In addition to the variable and fixed costs we introduced two long-term costs, opportunity and financial costs:

vi) Opportunity cost $\left(\operatorname{Co\sigma }_{v}\right)$ : is the cost of using the capital invested, as a function of the capital invested: $\operatorname{Co}_{v}=c 6 \cdot K_{v}$, where $\mathrm{c} 6$ is the opportunity cost of capital, taken as the interest rate for long-term bonds of the Spanish Treasury and $K_{v}$ is the total investment or capital in vessel $v$.

vii) Financial cost $\left(\mathrm{Co}_{v}\right)$ : is the depreciation and interest on bank loans. In case of negative profits, debts arise and any further investment or maintenance requires bank loans. Co 7 depends on banking interest rates $(c 7)$ and the individual debt incurred $\left(D_{v}\right)$.

$$
\operatorname{Co7}_{v}=c 7 \cdot D_{v}
$$

$D_{v}$ has an upper limit (maximum debt accepted by banks) depending on the total capital invested, as the bank is not willing to lend more than $d_{m} \cdot K_{v}$, where $d_{m}$ is a maximal percentage of loan authorized by the bank (in our simulations fixed at $80 \%$ ).

The net profits for each vessel are computed as:

$$
P_{v}=Y_{v}^{T}-\left(C o 1_{v}+C o 2_{v}+C o 3_{v}+C o 4_{v}+C o 5_{v}+C o 6_{v}+C o 7_{v}\right) .
$$

\section{Effort and catchability dynamics}

Based on the net profits obtained by each vessel at each iteration, we modeled the individual dynamics of effort and catchability following the following set of behavioural rules (Lleonart et al. 2003):

1. If the profits for each vessel were positive, the vessel increased the effort by a factor $\Delta_{v}$, up to a maximum allowed by the manager or physically possible (i.e., number of working days in the year). The factor $\Delta_{v}$ was computed empirically for each vessel analyzing the year-to-year variations in individual fishing effort (7\% annual increase on average). The level of effort deployed by each vessel in the red shrimp fishery for the year 0 of the simulations was that observed for the 1998-1999 sampling. Additionally, 10\% of the profits were directed at increasing the capital of the vessel, representing indirectly an increase in the catchability coefficient (see below).

2. If the profits were negative but bank loans could still be obtained, the vessel increased the effort as in case (1), but no internal investment is carried out and additional costs were incurred in $t+1$ to meet the financial costs.

3. If the profits were negative and it was not possible to obtain more bank credit, but the unavoidable part of the flexible costs could still be met, the vessel would reduce the avoidable costs, in order to try to increase the effort by $\Delta_{v}$. If the avoidable costs could not be met, then the vessel would reduce effort by $\Delta_{v}^{\prime} \cdot \Delta_{v}^{\prime}$ was obtained empirically by analyzing the year-to-year variations of individual effort and resulted in a reduction to $85 \%$, on average, from one year to the next. The capital of the vessel was reduced, based on the amount of losses.

4. If the profits were negative for year $t$ and none of the costs could be met, the vessel was removed from the fishery at the next iteration.

At all times in the simulation, a decommission price of $5000 € \mathrm{t}^{-1}$ gross tonnage was used, whereby the vessels whose capital was smaller than the decommission value would be removed from the fishery.

The dynamics of the fishing power $\left(q_{t, v}\right)$ of each vessel were modeled by considering a conservative interannual $1 \%$ $(\tau)$ increase in fishing power (Eide et al. 2003; Ulrich and Marchal 2002), related to the increase in investment of the vessels:

$$
q_{t, v}=\tau^{t} q_{t-1, v}
$$


The value of $\tau$ chosen is within the values reported in the literature for other fisheries (e.g., 2-3\% in Lindeb $\varnothing 2001$, or 1-4\% in Phillips and Melville-Smith 2005).

At the next iteration of the simulation the fishing mortality applied by the fleet to each cohort will be the product of the total catchability, fishing effort, and selectivity:

$$
\begin{aligned}
q_{t, f l, a} & =Q_{f l, a} \sum_{v} q_{t, v}, \\
E_{t, f l} & =\left(\sum_{v} p E f f_{t, v}\right) N F D_{f l} N H D_{f l}
\end{aligned}
$$

and

$$
F_{t, f l, a}=E_{t, f l} q_{t, f l, a} S_{t, f l, a} .
$$

\section{Management strategies - Simulation scenarios}

For each of the two fisheries analyzed here (Barcelona and Blanes shrimp fisheries), four scenarios were run, simulating a set of 3 alternative management measures against the status quo (scenario 0). The time horizon of the simulations was 15 years, taking 1999 as year 0 , and the number of stochastic iterations for each run was 100 . Scenario 0 was the base scenario, simulating the likely development of the fishery if no management action was taken. Scenario 1 simulated the impact of removing the tax exemption on the fuel price (which amounted to $50 \%$ of the price of the fuel in 1999), resulting in an increase of the costs of the fishing effort. Scenario 2 simulated the impact of a management measure aiming at keeping the effort at current (1998-1999) levels, i.e. no increase in number of days at seas was possible even with positive profits. Scenario 3 simulated the impact of improving the selectivity for cohorts 0,1 and 2 by reducing the selectivity factor for these age groups from 1 to 0.5 (Ragonese et al. 2001). We examined the results of each scenario run at the short (1-3 years after the management event) and medium-term (more than 3 years) (Brander 2003), by analyzing the evolution of different biological and economic indicators: the spawning stock biomass / fishing mortality precautionary plot, total production of the target species, fleet size and fleet profits. The results are presented as mean values of the 100 simulation runs with 5 and 95 percentiles.

\section{Results}

In addition to current management (no changes in status quo of 1999) we evaluate 3 management strategies for the two red shrimp fisheries. We compare the performance of the 3 management strategies using 4 indicators: catch, profits, spawning stock biomass (SSB) and fishing mortality (F). The latter two are compared against target and limit reference points (Kell et al. 2006), which are defined as $\operatorname{SSB}_{\mathrm{F}(0.1)}$ and $\mathrm{SSB}_{\mathrm{F}(\mathrm{MSY})}$ respectively.

\section{Barcelona red shrimp fishery}

The base scenario (Scenario 0) showed the progressive overexploitation of the stock, from a production of $64 \mathrm{t}$ in 1999 to around $30 \mathrm{t}$ at present (2004, note real catches from 1999 to 2004 overlaid in Fig. 5) and less than $20 \mathrm{t}$ at the end of the simulation run. The probability of negative profits for the fleet was positive after year 5 , and by year 12 over half of the simulation runs predicted negative profits for the fleet (Fig. 6). Due to the negative returns, only 14 vessels down from 18 would remain in activity at the end of the simulation run. The precautionary plot shows that the path of the fishery progresses far beyond the limit reference points (Fig. 7).

Removing the fuel subsidy to the fleet after year 5 (Scenario 1) has a negative impact on the economy of the vessels, reducing the total number of vessels from 18 to 13 at the end of the simulation and producing over half of the simulations with negative profits after year 5 (Fig. 6). Neither catches (Fig. 5) nor spawning stock biomass (Fig. 7) would recover in the medium-term (15 years) with this management measure.

Limiting the effort at 1998/1999 levels by year 5 (Scenario 2) would allow to maintain present-level catches (around 30 t, Fig. 3) in the short and medium-term, allowing to keep fishing mortality below the limit value of 0.87 , although the spawning stock would not necessarily rebuild (Fig. 7). Profits would remain positive for more than half of the simulation runs, although negative profits appeared after year five (Fig. 6). The number of vessels remaining in the fishery would decrease from 18 to 15 .

Improving the selectivity factor for age groups 0,1 and 2 after year 5 (Scenario 3) would not prevent fishing mortality increasing beyond the limit reference point (Fig. 7), but catches would increase steadily after year 6 to around $40 \mathrm{t}$ annually for the end of the simulation horizon (Fig. 5). Profits would also increase with time after the implementation of the management measure, reducing the probability of negative profits to around $10 \%$ of the simulation runs (Fig. 6). The number of vessels remaining in the fishery would drop to 15 .

\section{Blanes red shrimp fishery}

For the base scenario (Scenario 0) the situation is very different from the Barcelona fishery. Catches are predicted to remain stable or increase slightly in the medium-term -from the current 85 t to near $100 \mathrm{t}$ at year 15 (Fig. 4, note overlaid catch series for the period 1999-2004). The pattern observed for the catches is likely to be reflected directly in the profits for the fleet, with an average increase of $10 \%$ in the 15 -year horizon (Fig. 5). Naturally, given that all simulation runs predicted positive profits for the fleet, no vessels would disappear from the fleet in this scenario. The path of the fishery revolved around the target fishing mortality and the limit biomass reference points (Fig. 7).

Removing the fuel subsidy to the fleet after year 10 (Scenario 1) had a slight impact on the profits of the fleet (Fig. 5), but in no case these were negative or any vessel disappeared from the fleet. No appreciable differences with respect to Scenario 0 are apparent, neither in the catches (Fig. 4) nor in the precautionary plot (Fig. 6).

Limiting the fishing effort current levels (Scenario 2) resulted in a higher levels of biomass and catches for the fishery (from the current $85 \mathrm{t}$ up to an average $142 \mathrm{t}$ in the 15 year horizon: a $167 \%$ increase; Fig. 5). A corresponding increase in 

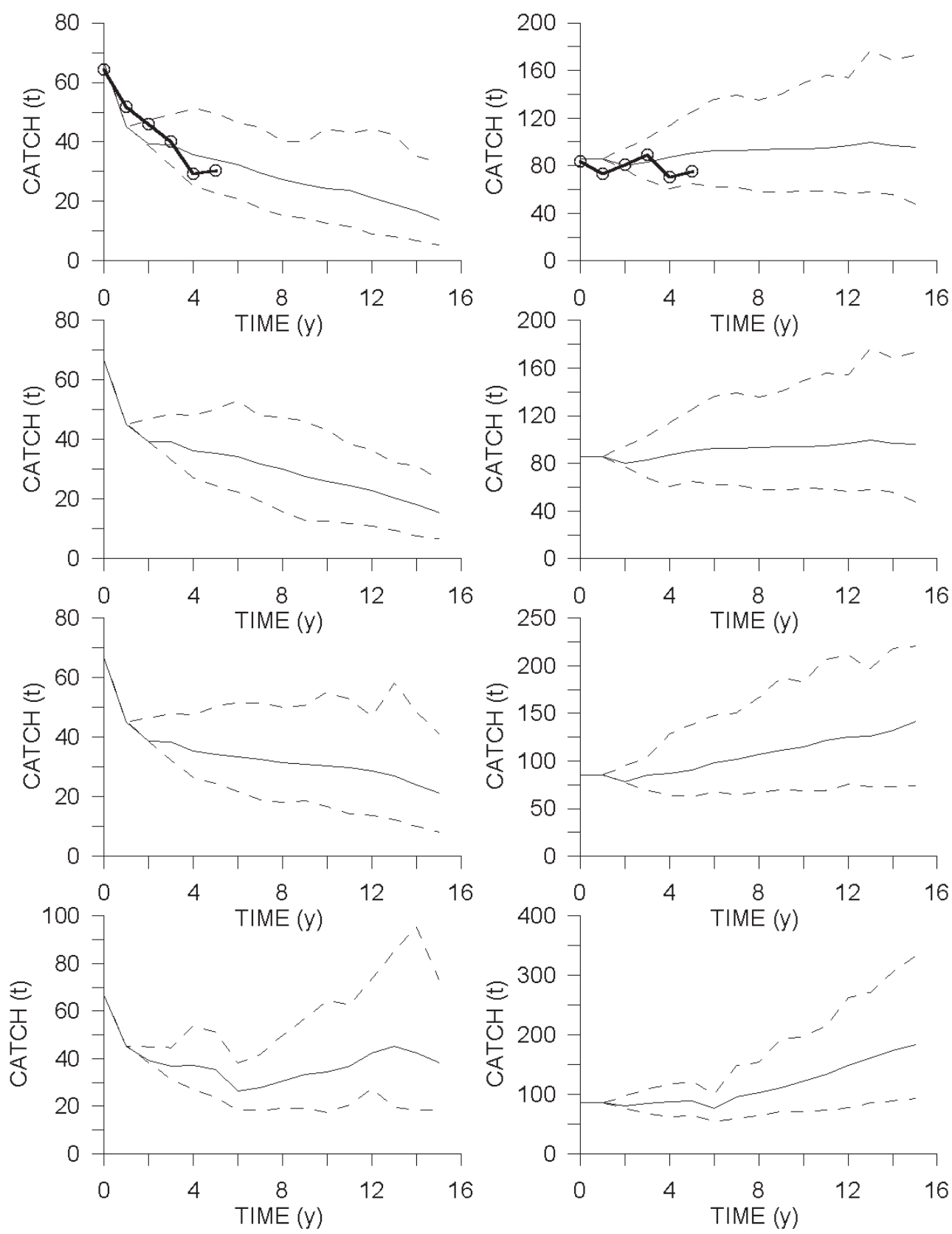

Fig. 5. Simulation of catches (t) showing the mean and 95\% confidence intervals of 100 iterations. Left, Barcelona fishery; right, Blanes fishery. From top to bottom: Scenario 0, 1, 2 and 3 (see text). Circles represent observed catches in the period 1999-2004.

profits for the fleet can be predicted (Fig. 6). The precautionary plot shows an important recovery in the spawning biomass, with fishing mortality remaining below the target reference point and spawning biomass increasing towards the target reference point (Fig. 7).

Improving the selectivity factor after year 5 (Scenario 3) shows a very important increase in catches at the end of the simulation horizon (from the current $85 \mathrm{t}$ up to $184 \mathrm{t}$ : a $116 \%$ increase, Fig. 5), although a short-term decline in catches in year 6 can be predicted. A very similar pattern emerged for profits (Fig. 6). The precautionary plot shows that the fishery at the end of the simulation period is situated above the target SSB point and below the target fishing mortality (Fig. 7).

\section{Discussion}

The deep-water trawl fishery in the NW Mediterranean is a very lucrative fishery, so there is a strong incentive to increase effort and overexploit the resource. Our bio-economic model could well mimic the reality of these fisheries for the test period 1999-2004, where the catches observed and the catches predicted by the model are reasonably close (Fig. 4).

In the Barcelona fishery, where the overexploitation situation is more acute, vessels that are ill-prepared to meet the high costs incurred would disappear from the fishery (between 3 and 5 vessels, depending on the scenario). The base scenario for the Barcelona fishery showed that if red shrimp 

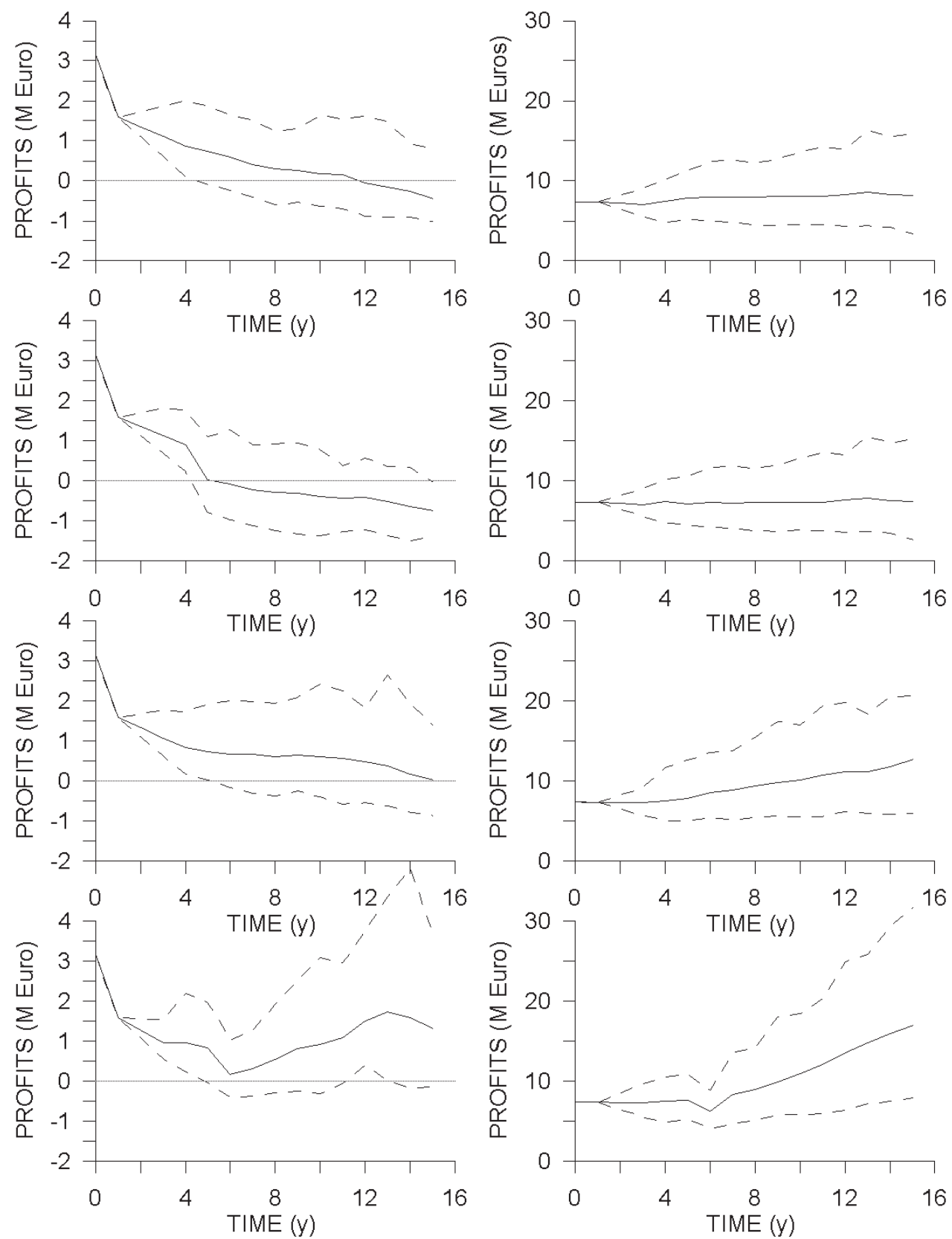

Fig. 6. Simulation of profits (€). Left, Barcelona fishery; right, Blanes fishery. From top to bottom: Scenario 0, 1, 2 and 3 (see text).

fisheries are not specifically managed, the situation of overexploitation will worsen in the mid to long-term with decreasing profits and catches. Removing the exemption of fuel tax (Scenario 1) without accompanying measures on effort would not reduce overexploitation, and would increase the overall economic losses of the fleet, although the remaining vessels would be better off. These results were clearer in the Barcelona fishery than in Blanes fishery (Fig. 5). Considering the current worldwide increase in fuel price, the economic losses sustained by the deep trawl fleets will probably worsen in the near future. Limiting the effort to current levels (Scenario 2) clearly reduced overexploitation of the resource, allowing some recovery of a heavily exploited fishery (Barcelona) or producing higher catches and profits in long-term for a lightly exploited case (Blanes). Improving the selectivity of age groups 0,1 and 2 (Scenario 3 ) helped counter overexploitation rates and produced similar results to scenario 2, although with higher long-term catches and profits. Improving the selectivity of age group 2 would also help increase the SSB, as this age group comprises the size of $50 \%$ maturity.

The differences between the Barcelona and Blanes fishery stem probably in the different location of the fishing grounds in the two ports. The Barcelona fishery is mostly conducted over the middle continental slope (400-800 m depth) relatively near shore (20-30 nautical miles from port), while the Blanes port is located near a submarine canyon with steep slope and relatively difficult fishing grounds (Fig. 1; Sardà et al. 1997; Tudela et al. 2003). 

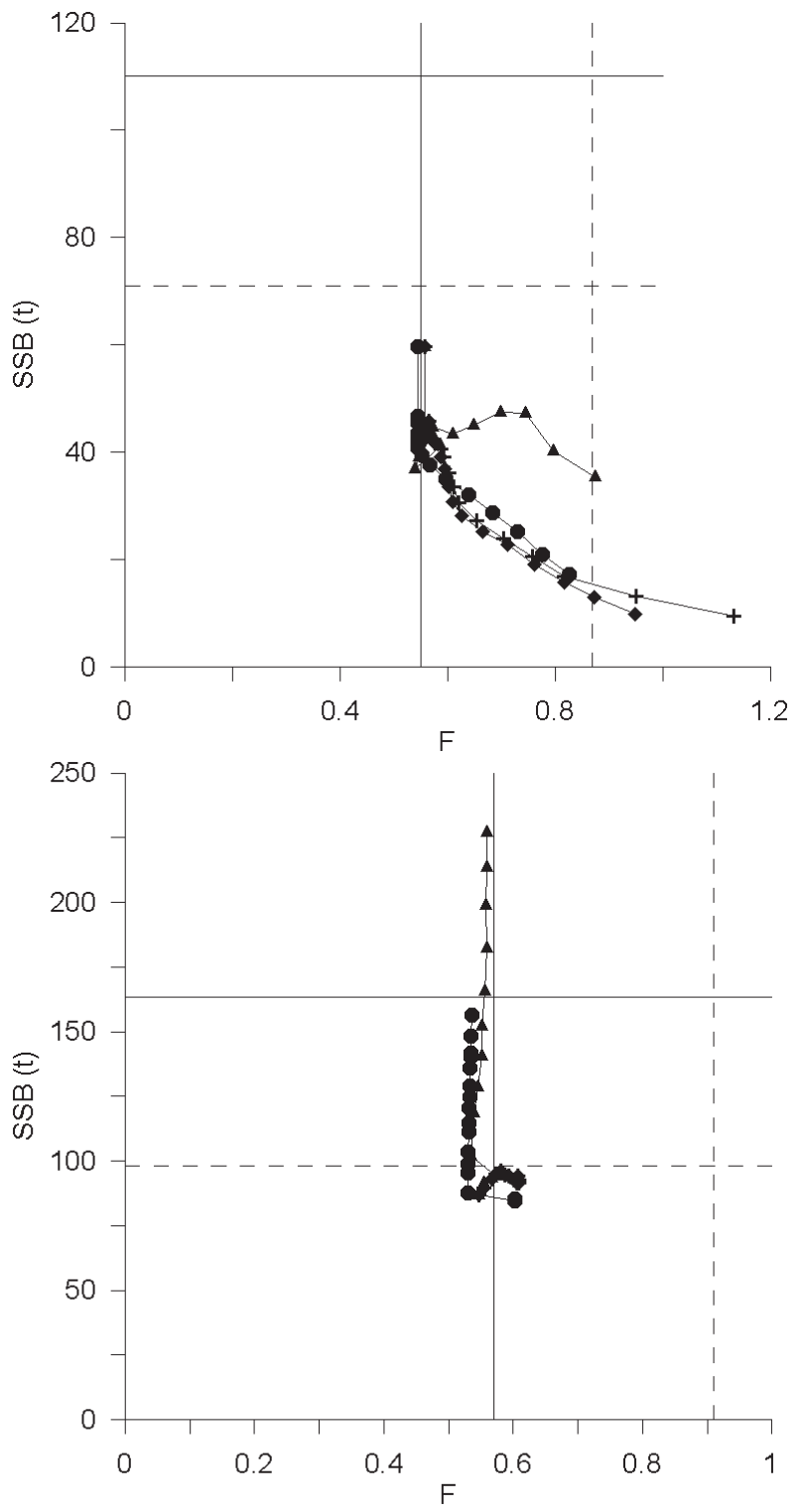

Fig. 7. Precautionary plots (Fishing mortality and Spawning Stock Biomass). Top, Barcelona fishery; bottom, Blanes fishery. From top to bottom: Scenario 0, 1, 2 and 3 (see text). Solid lines are precautionary reference points and dotted lines are target reference points. Diamonds: Scenario 0, Crosses: Scenario 1, Circles: Scenario 2, Triangles: Scenario 3.

It is difficult to compare our results with other studies, because there are no published references of the consequence of alternative management measures on other Aristeus antennatus fisheries in the Mediterranean. Recently, Guijarro and Massutí (2006) analysed the impact of changing the mesh type for deep-water crustacean fisheries in the Balearic islands. Their analyses showed that changing from the current $40-\mathrm{mm}$ diamond mesh size to an alternative $40-\mathrm{mm}$ square mesh size would allow for the escapement of smaller individuals of $A$. antennatus, and other by-catch species, similar to our Scenario 3. Their results show that the short-term loss in catches and revenues would be quickly offset by the higher
Table 4. Net present value of the red shrimp fisheries in Barcelona and Blanes over the 15-year simulation period (taking a discount rate of $5 \%$ ) under different management strategies, million $€$. Average value with $95 \%$ confidence intervals of 100 simulations.

\begin{tabular}{lll}
\hline & Barcelona & Blanes \\
\hline Scenario 0 & $8.99(2.33,19.25)$ & $87.77(59.53,129.03)$ \\
Scenario 1 & $5.38(-1.64,14.26)$ & $82.87(54.63,124.13)$ \\
Scenario 2 & $11.12(3.64,22.94)$ & $100.81(66.85,152.31)$ \\
Scenario 3 & $13.65(5.25,27.74)$ & $106.89(68.04,164.18)$ \\
\hline
\end{tabular}

weight and prices fetched by larger individuals, ensuring maintaining economic efficiency over the medium and long-term.

The main difference between our model and other bioeconomic simulation fisheries models (Sparre and Willmann 1993; Holland 2000; Ulrich et al. 2002a) is the treatment of the fleets at the level of individual vessels, thus allowing for the analysis of the evolution of each vessel in the fishery from different starting points (i.e. set of parameters). Although the cost structure is primarily based on empirical study of Mediterranean fisheries, the model presented here can be adapted to other small-scale fisheries, such as the Pernambuco coastal gillnet and longline fisheries (Mattos et al., in press). Other differences of our model with other bioeconomic fisheries models (BECHAMEL in Ulrich et al. 2002a) include its dynamic character, whereby effort and catchability, and hence fishing mortality, is evaluated at each iteration as a function of the economic performance of the individual vessels in the previous iteration.

A drawback of the model (especially in the biological submodel) is that it relies heavily on the availability of good assessments of the population and fishing mortality for the main species, which are notoriously difficult to conduct in areas such as the Mediterranean, or intertropical fisheries. The estimation of economic parameters on a vessel-by-vessel scale can also be seen as a limitation of the model, considering the difficulty in obtaining these parameters in some less well-studied fisheries.

The robustness of the results in our model, and similar bioeconomic fisheries models, is critically dependent on parameter estimation and the error structure of the parameters (Holland 2000; Holland et al. 2005). Here we have focused only in assessing the error structure of the stock / recruitment relationship, but other sources of error or uncertainty may arise from the natural mortality process or the investment dynamics of individual fishing firms (vessels). As stressed by Kell et al. (2006), the issues of parameter uncertainty must be analyzed with more detail and deserve further attention in future studies.

Comparing the performance of the management strategies on two stocks, one heavily fished and the other moderately so, we show that none of these management measures is able to substantially redress the situation of a heavily fished stock, implying that for the full recovery of heavily fished red shrimp stocks in this and other Mediterranean areas even stricter management measures should be considered. As shown by Kell et al. (2006) adhering strictly to the precautionary approach for overexploited fisheries may imply setting very conservative (low) effort levels, which may be difficult to accept by fisheries managers. 
Acknowledgements. We thank Mr. X. Márquez and Mr. P. Jorquera, of the Blanes and Barcelona Fishers' Associations, respectively, for access to their computerized daily fish sales database. This study was partly funded by the European Commission through research projects COCTEL (ref. EC DG XIV Copemed-FAO C97/018) and BEMMFISH (ref. EC Q5RS-2001-01533).

\section{References}

Bas C., Macpherson E., Sardà F., 1985, Fish and fishermen. The exploitable trophic levels. In: Margalef R. (Ed.) The Western Mediterranean, Oxford, Pergamon Press, pp. 296-316.

Brander K., 2003, What kinds of fish stock predictions do we need and what kinds of information will help us to make better predictions? Sci. Mar. 67 (Suppl. 1), 21-33.

Carbonell A., Carbonell M., Demestre M., Grau A., Monserrat S., 1999, The red shrimp Aristeus antennatus (Risso, 1816) fishery and biology in the Balearic Islands, Western Mediterranean. Fish. Res. 44, 1-13.

Carbonell A., García M., Pereda P., Esteban A., Pomar G., Gaza M., Torres A., Gil J.L.P., 2001, The deep-water red shrimp fishery in the Spanish Mediterranean Sea. Scientific Council Research Documents of the Northwest Atlantic Fisheries Organization No. $01 / 85,8 \mathrm{p}$.

Christensen, S., 1997, Evaluation of management strategies - a bioeconomic approach applied to the Greenland shrimp fishery. ICES J. Mar. Sci. 54, 412-426.

Demestre M., Martín P., 1993, Optimum exploitation of a demersal resource in the western Mediterranean: the fishery of the deepwater shrimp Aristeus antennatus (Risso, 1816). Sci. Mar. 57, 175-182.

Demestre M., Lleonart J., 1993, Population dynamics of Aristeus antennatus (Decapoda: Dendrobranchiata) in the northwestern Mediterranean. Sci. Mar. 57, 183-189.

Eide A., Skjold F., Olsen F., Flaaten O., 2003, Harvest functions: The Norwegian bottom trawl cod fisheries. Mar. Res. Econ. 18, 81-93.

García-Rodríguez M., Esteban A., 1999, On the biology and fishery of Aristeus antennatus (Risso, 1816), (Decapoda, Dendrobranchiata) in the Ibiza Channel (Balearic Islands, Spain). Sci. Mar. 63, 27-37.

Guijarro B., Massutí E., 2006, Selectivity of diamond- and squaremesh codends in the deep-water crustacean trawl fishery off the Balearic islands (western Mediterranean). ICES J. Mar. Sci. 63, 52-67.

Holland D.S., 2000, A bioeconomic model of marine sanctuaries on Georges Bank. Can. J. Fish. Aquat. Sci. 57, 1307-1319.

Holland D.S., Bentley N., Lallemand P., 2005, A bioeconomic analysis of management strategies for rebuilding and maintenance of the NSS rock lobster (Jasus edwardsii) stock in southern New Zealand. Can. J. Fish. Aquat. Sci. 62, 1553-159.

Holland D.S., Schnier K.E., 2006, Individual habitat quotas for fisheries. J. Environ. Econ. Manage. 51, 72-92.

Horwood J.W. (Ed.), 1994, Modelling of fisheries management strategies. Ministry of Agriculture, Fisheries and Food, Directorate of Fisheries Research, Fisheries Laboratory, UK. Privately published.

Kell L.T, Pilling G.M., Kirkwood G.P., Pastoors M.A., Mesnil B., Korsbrekke K., Abaunza P., Aps R., Biseau A., Kunzlik P., Needle C.L., Roel B.A., Ulrich C., 2006. An evaluation of multiannual management strategies for roundfish stocks. ICES J. Mar. Sci. 63, 12-24.

Lindeb $\varnothing$ E., 2001, Technological progress and capacity estimations. Management implications for the Danish cod trawl fishery. Mimeo.
Lleonart J., Salat, J., 1997, VIT: Software for fishery analysis. Rome, FAO Computerized Information Ser. (Fisheries) 11, 1-107.

Lleonart J., Franquesa R., Salat J., Oliver P., 1996, "Heures" a bioeconomic model for Mediterranean fisheries, towards an approach for the evaluation of management strategies. Sci. Mar. 60, 427-430.

Lleonart J., Maynou F., Franquesa R., 1999, A bioeconomic model for Mediterranean fisheries. Fish. Econ. Newslet. 48, 1-16.

Lleonart J., Maynou F., Recasens L., Franquesa R., 2003, A bioeconomic model for Mediterranean fisheries, the hake off Catalonia (western Mediterranean) as a case study. Sci. Mar. 67 (suppl. 1), 337-351.

Mattos S., Maynou F., Franquesa R., in press, A bioeconomic analysis of the handline and gillnet coastal fisheries of Pernamuco State, northeastern Brazil. Sci. Mar.

Mesnil B., Shepherd J.G., 1990, A hybrid age- and length-structured model for assessing regulatory measures in multiple-species, multiple-fleet fisheries. J. Cons. Intern. Explor. Mer 47, 115-132.

Phillips B.F., Melville-Smith R., 2005, Sustainability of the western rock lobster fishery: A review of past progress and future challenges. Bull. Mar. Sci. 76, 485-500.

Ragonese S., Zagra M., Di Stefano L., Bianchini M., 2001, Effect of codend mesh size on the performance of the deep-water bottom trawl used in the red shrimp fishery in the Strait of Sicily (Mediterranean Sea). Hydrobiologia 449, 279-291.

Sardà F. (coord.), 2000, Analysis of the Mediterranean (including North Africa) deep-sea shrimps fishery: catches, effort and economics (EC, DG XIV, C97/018). http://www . faocopemed.org/vldocs/0000191/ deepseashrimps.pdf

Sardà F., Cartes J.E., Norbis W., 1994, Spatio-temporal structure of the deep-water shrimp Aristeus antennatus (Decapoda: Aristeidae) population in the western Mediterranean. Fish. Bull. 92, 599-607.

Sardà F., Maynou F., Talló L., 1997, Seasonal and spatial mobility patterns of rose shrimp Aristeus antennatus in the Western Mediterranean. Mar. Ecol. Prog. Ser. 159, 133-141.

Seijo J.C., Defeo O., Salas S., 1998, Fisheries bioeconomics: Theory, modelling and management. FAO Fish. Tech. Pap. 368, 1-108.

Sparre P., Willmann R., 1993, Software for bio-economic analysis of fisheries. BEAM 4. Analytical bio-economic simulation of space-structured multispecies and multi-fleet fisheries. FAO Computerized Information Series (Fisheries), 3 (2 vol.).

Tobar R., and Sardà F., 1987, Análisis de la evolución de las capturas de gamba rosada, Aristeus antennatus (Risso 1816), en los últimos decenios en Cataluña. Inf. Téc. Invest. Pesq. 142, 1-20.

Tudela S., Sardà F., Maynou F., Demestre M., 2003, Influence of submarine canyons on the distribution of the deep-water shrimp, Aristeus antennatus (Risso 1816) in the NW Mediterranean. Crustaceana 76, 217-226.

Ulrich C., Marchal P., 2002, Sensitivity if some biological reference points to shifts in exploitation patterns and inputs uncertainty for three North Sea demersal stocks. Fish. Res. 58, 153-169

Ulrich C., Le Gallic B., Dunn M.R., Gascuel D., 2002a, A multispecies multi-fleet bioeconomic simulation model for the English Channel artisanal fisheries. Fish. Res. 58, 379-401.

Ulrich C., Pascoe S., Sparre P.J., De Wilde J.-W., Marchal P., 2002b, Influence of trends in fishing power on bioeconomics in the North Sea flatfish fishery regulated by catches or by effort quotas. Can. J. Fish. Aquat. Sci. 59, 829-843.

Werner F.E., Quinlan J.A., Lough R.G., Lynch D.R., 2001, Spatiallyexplicit individual based modeling of marine populations: a review of the advances in the 1990s. Sarsia 86, 411-421. 